JRRD

\title{
PTSD is negatively associated with physical performance and physical function in older overweight military Veterans
}

\author{
Katherine S. Hall, PhD; ${ }^{1-3 *}$ Jean C. Beckham, PhD; ${ }^{4-5}$ Hayden B. Bosworth, PhD; ${ }^{2-3,5-6}$ Richard Sloane, MS; $^{2}$ \\ Carl F. Pieper, DrPH; ${ }^{2}$ Miriam C. Morey, PhD $^{1-3,6}$ \\ ${ }^{1}$ Geriatric Research, Education, and Clinical Center, Department of Veterans Affairs (VA) Medical Center, Durham, \\ $N C ;{ }^{2}$ Claude D. Pepper Older Americans Independence Center/Center for Aging and ${ }^{3}$ Department of Medicine, Duke \\ University Medical Center, Durham, NC; ${ }^{4}$ VA Research Service/Veterans Integrated Service Network 6 Mental Illness \\ Research, Education, and Clinical Center, VA Medical Center, Durham, NC; ${ }^{5}$ Department of Psychiatry and Behav- \\ ioral Sciences, Duke University Medical Center, Durham, NC; ${ }^{6}$ Center for Health Services Research and Development, \\ VA Medical Center, Durham, NC
}

\begin{abstract}
This study examines the effect of posttraumatic stress disorder (PTSD) on function and physical performance in older overweight military Veterans with comorbid conditions. This is a secondary data analysis of older Veterans (mean age $=62.9 \mathrm{yr}$ ) participating in a physical activity counseling trial. Study participants with PTSD $(n=67)$ and without PTSD $(n=235)$ were identified. Self-reported physical function (36-item Short Form Health Survey) and directly measured physical performance (mobility, aerobic endurance, strength) were assessed. Multivariate analyses of variance controlling for demographic factors and psychiatric disorders demonstrated significant physical impairment among those with PTSD. PTSD was negatively associated with self-reported physical function, functioning in daily activities, and general health $(p<0.01)$. Those with PTSD also performed significantly worse on tests of lower-limb function $(p<0.05)$. Despite being significantly younger, Veterans with PTSD had comparable scores on gait speed, aerobic endurance, grip strength, and bodily pain compared with Veterans without PTSD. This study provides preliminary data for the negative association between PTSD and physical function in older military Veterans. These data highlight the importance of ongoing monitoring of physical performance among returning Veterans with PTSD and intervening in older overweight Veterans with PTSD, whose physical performance scores are indicative of accelerated risk of premature functional aging.
\end{abstract}

Clinical Trial Registration: ClinicalTrials.gov; NCT00594399; "Veterans Enhanced Fitness Study"; http://www.clinicaltrials.gov/ ct2/show/NCT00594399
Key words: aging, comorbid, function, geriatrics, health, mobility, physical performance, psychological, PTSD, SF-36.

\section{INTRODUCTION}

The Veterans Health Administration (VHA) is experiencing a graying effect similar to that observed in the general population. Of the nation's 22.3 million military Veterans, 43 percent (9.6 million) are aged 65 and older [1]. Another 8 million aging Vietnam-era Veterans are joining this older cohort and bringing increased challenges to

\footnotetext{
Abbreviations: 6MWT = six-minute walk test, ADL = activities of daily living, BMI = body mass index, EMR = electronic medical record, ICD-9 = International Classification of Diseases-9th Revision, MANOVA = multivariate analysis of variance, PCS = Physical Component Summary, PTSD = posttraumatic stress disorder, SF-36 $=36$-item Short Form Health Survey, SPPB = Short Physical Performance Battery, VA = Department of Veterans Affairs, VHA = Veterans Health Administration.

*Address all correspondence to Katherine S. Hall, PhD; Durham VA Medical Center, GRECC (182), 508 Fulton St, Durham, NC 27705; 919-286-0411, ext 6734; fax: 919-2866823. Email: katherine.hall@duke.edu http://dx.doi.org/10.1682/JRRD.2013.04.0091
} 
the VHA, including increased cases of posttraumatic stress disorder (PTSD). Although PTSD symptoms may reduce or disappear in many after therapy, symptoms may persist for other individuals [2]. Recent estimates suggest that the number of Vietnam-era military Veterans diagnosed with PTSD is well over the half-million mark, with symptoms perpetuating into late life [3-4]. With members of the Armed Forces returning from service in Iraq and Afghanistan, thousands of younger Veterans will turn to the VHA for the special care and services only it can provide. As these Veterans advance in age, they are likely to be at risk of not only certain deployment-related health conditions but also chronic diseases associated with lifestyle factors, swelling the ranks of those who will ultimately require mental health, medical, and rehabilitation services.

Military Veterans with psychiatric disorders are at increased risk for obesity and other features of the metabolic syndrome. Substantial evidence from clinical and epidemiologic studies documents pervasive overweight and obesity, cardiovascular disease, and hyperglycemia/ type 2 diabetes in military Veterans with PTSD [5-11]. Although the mechanisms of this association continue to be explored, maladaptive psychological (e.g., depression), behavioral (e.g., substance abuse), and biological (e.g., noradrenergic and hypothalamic-pituitary-adrenal axis dysregulation) responses have all been identified as potential pathways to secondary negative health outcomes among those with PTSD (see Schnurr and Green [12] and Friedman and McEwen [13] for a comprehensive review).

Another important factor in the development and progression of chronic diseases is age. The risks for chronic conditions increase significantly with increasing age, and older adults often have multiple conditions at the same time. Impaired physical function and mobility are a common consequence of comorbid disease processes and are therefore a useful aggregate indicator of age-related decline in physical health. The importance of PTSD symptoms in later life and the extent to which PTSD symptoms may precipitate or exacerbate symptoms of chronic conditions (e.g., functional impairments) in older adults remains to be explored.

Accumulating evidence from epidemiologic studies shows that PTSD is associated with poor functional status as well. To date, only a handful of studies have examined the potential link between PTSD and physical function in older adults. The largest of these studies was conducted in a nationally representative sample of U.S. older adults
[14] and reported significantly poorer self-reported physical functioning, role-physical limitations, bodily pain, and general health among older adults with PTSD than older adults without PTSD. Similar results have been reported in middle-aged military Veteran samples [15-17].

The noted studies notwithstanding, there are several important deficits in the current literature regarding PTSD and health. First, many studies in this area have focused on medical disorders without regard for the functional sequelae, which are major sources of economic expense, anxiety, increased healthcare utilization, and deterioration of quality of life, particularly among older adults [18-19]. Second, few of these studies have controlled for sociodemographic characteristics or comorbid psychological conditions, such as depression, when examining these associations. Third, we are not aware of any studies that have examined the association between PTSD and function in older samples of military Veterans. And finally, these studies have relied exclusively on selfreport measures of function. While self-report measures of function are important indicators of limitation in daily activities, objective measures of physical performance provide additional information that can be used to establish clinical risk. An innovation of this article is that, to our knowledge, we are the first to examine function with the inclusion of directly measured physical performance in this population.

This article provides for the first time information on the effect of PTSD on objective assessments of physical function in a sample of older overweight military Veterans. Physical performance measures are increasingly an integral part of clinical care for older adults, particularly in the rehabilitation setting, because they have good predictive value of subsequent health and functional independence [20]. Performance measures of mobility, aerobic endurance, and strength have all been identified as important indicators of health and have been studied for the prediction of activities of daily living (ADL) disability, mobility disability, and mortality [21-25]. In this study, we seek to replicate and extend previous research by examining both self-reported physical function, which reflects the extent to which functional impairments affect daily activities, and performance-based measures of functional status, including mobility, strength, and aerobic endurance. We hypothesized that after adjustment for sociodemographic characteristics and depression, older overweight military Veterans with PTSD would report poorer physical functioning and would also perform 
worse on physical performance assessments than older overweight Veterans without PTSD.

\section{METHODS}

\section{Design Overview}

Analyses were conducted using data from the Enhanced Fitness Study, a physical activity counseling trial for older overweight Veterans with impaired glucose tolerance [26-27]. The data presented here are a secondary analysis comparing study participants with and without PTSD. The Enhanced Fitness Study compared the effects of a 12 mo home-based physical activity counseling intervention with usual care among older ( $\geq 60 \mathrm{yr}$ ) overweight Veterans. Although described in full detail elsewhere [26-27], the medical records of all age-eligible individuals from two large, area Department of Veterans Affairs (VA) clinics were prescreened for the following eligibility requirements: impaired fasting glucose (100$125 \mathrm{mg} / \mathrm{dL}$ ), no diagnosis of diabetes mellitus, glycosylated hemoglobin of less than 7 percent, and body mass index (BMI) between 25 and $45 \mathrm{~kg} / \mathrm{m}^{2}$. Individuals who exceeded current physical activity recommendations were excluded. Recruitment packets were mailed to 1,763 patients. Enrollment appointments were made for 561 (31.8\%) potentially eligible individuals, of whom 302 (53.8\%) were ultimately enrolled and randomized in the study. Recruitment of study participants began in 2008 and concluded in 2010. Baseline data from 302 older Veterans participating in the parent study were used for this analysis.

\section{Measures}

\section{Demographics and Biometrics}

Basic demographic and biometric data were collected during the intake appointment and included age, sex, race, and education. Height and weight were measured using a stadiometer and physician's scale, respectively. From the height and weight measurements we calculated BMI (kilograms per square meter).

\section{PTSD and Depression}

The electronic medical record (EMR) of each study participant was retrospectively reviewed for any documentation of PTSD (International Classification of Diseases-9th Revision [ICD-9] code 309.81) or depression
(ICD-9 codes 300.4, 296.2, 296.3, 311) in the notes. This EMR data pull was conducted after the parent study was underway and did not specify a time period for diagnosis. We also reviewed the "Active Problems" section of the EMR for inclusion of PTSD or depression. Only those patients who had a PTSD or depression diagnosis as indicated by the corresponding ICD-9 code and had this condition also listed under "Active Problems" were categorized as PTSD+ or Depression+ for this study.

\section{Number of Comorbidities}

Comorbidity status was assessed via self-report using a modified version of the 35-item Older Americans Resources and Services comorbidity index [28]. A sum of item responses creates a total comorbidity score reflecting the number of comorbidities reported. Sample items include arthritis, cancer, hypertension, and osteoporosis.

\section{Physical Health Functioning}

Physical health functioning was assessed using the 36-item Short Form Health Survey (SF-36) [29]. The physical health component of the SF-36 contains a Physical Component Summary (PCS) score and four healthrelated subscales: (1) Physical Function: limitation in a range of activities, (2) Role Functioning: difficulties and limitations performing daily activities, (3) Bodily Pain: intensity of bodily pain and the extent to which pain limits daily activities, and (4) General Health: subjective ratings of general health. Scale scores were standardized on a scale ranging from 0 to 100 , with higher scores representing better health functioning. The Mental Health Component Summary score and the mental health-related subscales of the SF-36 were not examined in this study.

\section{Physical Performance}

Lower-limb physical performance was measured using the Short Physical Performance Battery (SPPB [30]) and gait speed. The SPPB score is based on time to walk $8 \mathrm{ft}$ (usual walking pace in meters per second), chair rises (time to complete 5 stands), and standing balance (ability to hold side-by-stand, semitandem, and tandem stands for $10 \mathrm{~s}$ each). Each of the individual performance measures are scored on a scale of 0 (worst performance) to 4 (best performance). The overall physical performance score combines the results of the three test conditions, with scores ranging from 0 (worst performance) to 12 (best performance). Usual and rapid gait speed (in meters per second) was measured over an 8-foot walking 
path. Two trials were completed for each condition, with the best time for each test recorded.

\section{Aerobic Endurance}

Aerobic endurance, a measure of cardiorespiratory function, was assessed using the six-minute walk test (6MWT [31]). This is a self-paced assessment in which individuals choose their own intensity of exercise, with the goal of walking as far as possible in $6 \mathrm{~min}$. Greater distances walked reflect better aerobic endurance. This test has demonstrated excellent reliability and validity when compared with maximal oxygen uptake assessments in healthy older adults [20].

\section{Grip Strength}

Hand-grip strength was measured in the dominant hand using a hand dynamometer. Three trials, with brief pauses in between, were performed. Participants were instructed to exert their maximal grip, and the best of the three tests was scored in kilograms.

\section{Statistical Analysis}

Between-group analyses comparing individuals with and without PTSD were conducted across sociodemographic and physical function/performance variables using chi-square tests for dichotomous variables and $t$ tests for continuous variables.

Multivariate analysis of variance (MANOVA) was used to examine the independent effect of PTSD on selfreported functional health status and functional perfor- mance. Self-reported physical health status (SF-36) was examined in the first model, while physical performance was assessed in a second, separate, model. The MANOVA process of analysis involved two steps: (1) test of overall model significance and (2) test of effects for individual outcomes. Data analysis comprised two distinct steps for each model. An omnibus F-test of the overall model of PTSD and SF-36 outcomes was conducted and model parameters examined. Consistent with analytic guidelines, if results of the overall MANOVA were significant, we then proceeded to the second step, which included examination of the individual effects. These procedures were repeated for the second model: PTSD and physical performance outcomes. Basic assumptions of dependence, linearity, homogeneity of variance, and normality were evaluated and upheld for both MANOVA models [32]. All variance inflation factors were low, indicating little or no multicollinearity.

Post hoc analyses were used in both models to determine the independent effect of PTSD, controlling for the effects of age, race, BMI, education, number of comorbidities, and depression. Statistical analyses were performed using SAS (version 9.3, SAS Institute Inc; Cary, North Carolina).

\section{RESULTS}

Sample characteristics are presented in Table 1. Briefly, this sample was made up predominantly of Caucasian

Table 1.

Sample characteristics of older overweight Veterans with and without posttraumatic stress disorder (PTSD). Data shown as mean \pm standard deviation or \%.

\begin{tabular}{|c|c|c|c|c|}
\hline Variable & $\begin{array}{c}\text { Total Sample }^{*} \\
(N=302)\end{array}$ & $\begin{array}{l}\text { Without PTSD } \\
\quad(n=235)\end{array}$ & $\begin{array}{l}\text { With PTSD } \\
\quad(n=67)\end{array}$ & $\begin{array}{c}\text { With vs Without PTSD } \\
\text { (p-Value) }\end{array}$ \\
\hline \multicolumn{5}{|l|}{ Demographic } \\
\hline Age (yr) & $67.4 \pm 6.2$ & $68.6 \pm 6.2$ & $62.9 \pm 3.9$ & $<0.01$ \\
\hline Race & & & & $<0.01$ \\
\hline African American & 27.6 & 21.8 & 47.8 & - \\
\hline Caucasian & 70.4 & 76.5 & 49.3 & - \\
\hline Sex: Male & 96.7 & 96.6 & 97.0 & 0.87 \\
\hline Education: $\geq$ High School Graduate & 90.4 & 90.2 & 91.0 & 0.54 \\
\hline No. of Comorbidities & $4.1 \pm 2.4$ & $3.9 \pm 2.4$ & $4.5 \pm 2.3$ & 0.11 \\
\hline Body Mass Index $\left(\mathrm{kg} / \mathrm{m}^{2}\right)$ & $31.2 \pm 3.6$ & $31.2 \pm 3.6$ & $31.3 \pm 3.7$ & 0.85 \\
\hline \multicolumn{5}{|l|}{ Psychological } \\
\hline Depression: Yes & 27.5 & 18.7 & 58.2 & $<0.001$ \\
\hline
\end{tabular}


men between 60 and 89 yr of age. The average BMI of this sample was in the obese range $\left(31.2 \pm 3.6 \mathrm{~kg} / \mathrm{m}^{2}\right)$. This was expected, given the focus of the parent trial on overweight Veterans.

Of the total sample, 67 patients (22\%) were identified as having a PTSD diagnosis noted in the EMR. Veterans with PTSD were significantly $(p<0.05)$ younger, were less likely to be Caucasian, and had significantly higher rates of depression. No significant between-group differences were observed for number of comorbidities, education, or BMI. Bivariate correlations (not reported) demonstrated that number of comorbidities, BMI, and education were significantly associated with several of the outcome variables and were thus retained as covariates in the MANOVAs in addition to the other demographic variables that differed across the PTSD/no PTSD groups.

\section{Self-Reported Physical Function (SF-36)}

Mean scores on the PCS and the subscales of the SF-36 are presented in Table 2. Veterans with PTSD reported significantly poorer scores across all SF-36 subscales and the PCS than those without PTSD.

The multivariate test of the overall model for the SF36 PCS score and subscales was statistically significant $(F(5,290)=16.25, p<0.001))$, allowing us to then examine the individual parameter estimates for each of the outcome measures individually. Consistent with our hypothesis and previous literature, PTSD was associated with significantly $(p<0.05)$ poorer physical function, role-physical health, and general health when controlling for age, race, education, number of comorbidities, depression, and BMI. No significant effects of PTSD status were observed for the PCS or bodily pain. These results are presented in Table 3.

Post hoc interaction analyses were conducted to see whether race, depression, BMI, or comorbidities were driving the associations between PTSD and SF-36 scales. No significant interactions were observed.

\section{Physical Performance}

Mean scores on the physical performance assessments are presented in Table 2. Veterans with PTSD performed significantly worse on the SPPB and grip strength tests than those without PTSD. No significant betweengroup differences were observed for the $6 \mathrm{MWT}$ or gait speed measure.

The multivariate test of the overall model for the physical performance measures was statistically significant $(F(5,290)=2.76, p<0.05))$, allowing us to then examine the individual parameter estimates for each of the outcome measures individually. PTSD was associated with significantly $(p<0.05)$ poorer lower-limb function (SPPB) when controlling for age, race, education, number of comorbidities, depression, and BMI. Contrary to our hypothesis, no significant effects of PTSD were observed for gait speed, aerobic endurance, or grip strength. These results are presented in Table 3.

Table 2.

Physical function and physical performance by posttraumatic stress disorder (PTSD) status among older overweight Veterans with impaired glucose. Data shown as mean (standard error).

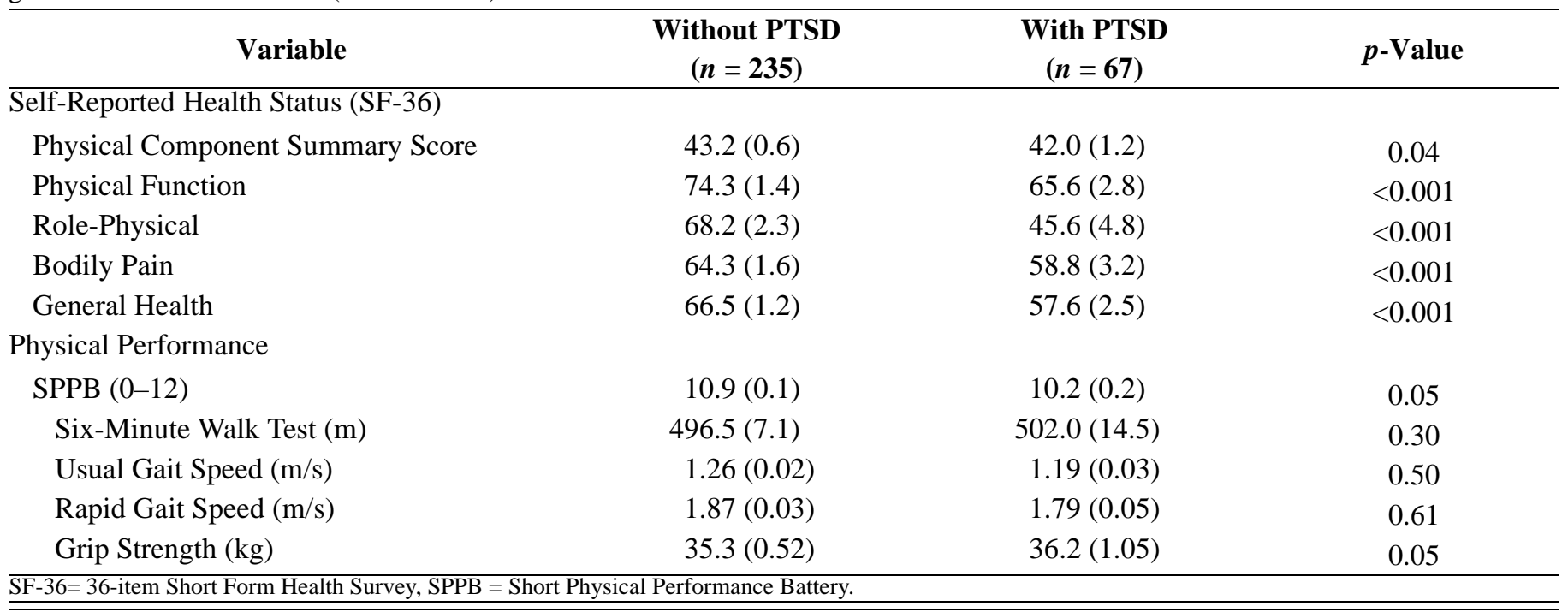


JRRD, Volume 51, Number 2, 2014

Table 3.

Multivariate analysis of variance testing effect of posttraumatic stress disorder on self-reported health and physical performance.

\begin{tabular}{|c|c|c|c|}
\hline Variable & Estimate & Standard Error & $p$-Value \\
\hline \multicolumn{4}{|l|}{ Self-Reported Health Status (SF-36) } \\
\hline Physical Component Summary Score & -0.95 & 1.45 & 0.51 \\
\hline Physical Function & -8.96 & 3.30 & 0.01 \\
\hline Bodily Pain & -4.74 & 3.78 & 0.21 \\
\hline General Health & -9.01 & 2.89 & $<0.01$ \\
\hline Six-Minute Walk Test (m) & 3.83 & 16.72 & 0.82 \\
\hline Usual Gait Speed (m/s) & -0.06 & 0.04 & 0.11 \\
\hline Rapid Gait Speed (m/s) & -0.05 & 0.06 & 0.37 \\
\hline Grip Strength (kg) & 0.63 & 1.23 & 0.61 \\
\hline
\end{tabular}

Post hoc interaction analyses were conducted to see whether race, depression, BMI, or comorbidities were driving the associations between PTSD and physical performance outcomes. No significant interactions were observed.

\section{DISCUSSION}

In a sample of 302 older overweight military Veterans, PTSD was associated with poor functional status and impaired physical performance after controlling for relevant demographic, biometric, and psychological factors. Our findings complement and extend existing research examining health status among individuals with PTSD by exploring the effect of PTSD on common functional sequelae of chronic disease. Of note, our study is the first to provide directly measured objective physical performance data indicative of functional morbidity in military Veterans with PTSD.

Consistent with previous studies of military Veterans, we observed significant effects of PTSD on self-rated health. Specifically, PTSD was significantly associated with impaired physical function, greater role limitations due to physical health, and worse general health perceptions in adjusted analyses. Recent evidence suggests that poor self-reported physical health status is associated with higher rates of healthcare utilization and higher medical costs in military Veterans [33-34]. Indeed, previous studies have shown that self-reported health has the same predictive power for higher resource use as other clinical data, including comorbidity counts, number of medical visits, and pharmacy-based information [35-37]. As such, these results have important implications for the VA medical system and primary care and rehabilitative services, in particular.

That PTSD was not significantly associated with the Bodily Pain scale of the SF-36 in adjusted analyses was surprising in light of previous studies that have documented a high prevalence of comorbid pain among military Veterans with PTSD [14-15,38]. The paucity of research exploring these relationships in older adult samples limits our ability to fully explore this finding. However, it is likely that these older Veterans with PTSD also experience chronic, as opposed to acute, pain [38]. Thus, one potential explanation is that over the years these Veterans have developed pain and/or PTSD coping strategies, both of which may positively affect pain symptoms and lessen the effect of pain on daily activities. Veterans with PTSD in our sample tended to have higher (better) bodily pain scores than the military Veterans with PTSD surveyed in other studies [16,39], lending some support to this interpretation. Further examination of the longitudinal trajectories of PTSD and pain symptoms in Veterans is warranted.

In addition to assessing self-reported physical health/ functioning, we included physical performance tests to explore the effect of PTSD on functional capacity. Guided by the substantial literature showing that PTSD is associated with biobehavioral risk factors and physical morbidity, we hypothesized that the functional consequences of physical morbidity would also be more severe 
among military Veterans with PTSD than those without PTSD. In adjusted models, PTSD was only significantly associated with the SPPB, a performance battery that includes tests of balance, lower-body leg strength, and walking. Despite being 6 yr younger on average, older overweight military Veterans with PTSD scored on average 0.7 points lower (worse) on the SPPB than their counterparts without PTSD. Although this difference appears small, differences of 0.5 on the SPPB are indicative of small, clinically meaningful differences [25]. These results suggest that older overweight military Veterans with PTSD are at increased risk for mobility disability and ADL disability [40] compared with those without PTSD.

Contrary to our hypothesis, PTSD was not significantly associated with aerobic endurance, gait speed, or grip strength in adjusted models. Given the vast literature demonstrating an association between PTSD and cardiovascular changes and heightened risk of cardiovascular and musculoskeletal conditions, we fully expected to see this reflected in worse physical performance. Instead, both groups of military Veterans demonstrated poor aerobic conditioning (with PTSD $=$ 25th percentile, without PTSD $=40$ th percentile) and grip strength (with PTSD = $10 \%$ below average, without PTSD $=15 \%$ below average) compared with age-matched national norms [4142]. Aerobic endurance is an important determinant of functional independence, exercise capacity, and all-cause morbidity and mortality. Low grip strength is associated with a greater likelihood of premature mortality, the development of disability, and prolonged length of stay after hospitalization or surgery in older adults [43]. Our results suggest that older overweight military Veterans at risk for diabetes, regardless of PTSD status, could benefit from lifestyle interventions to improve aerobic endurance and upper-body strength.

Our data suggest a premature functional aging effect of PTSD. Despite being an average 6 yr younger, those with PTSD performed at a level equal to, or worse, than the significantly older Veterans without PTSD on physical function assessments and self-reported health status. Of note, individuals with PTSD in this study still reported significantly greater limitations in daily activities due to functional impairments than did Veterans without PTSD, despite having similar functional capabilities. Research has consistently shown that patients' perceptions of health status are a significant predictor of healthcare utilization and quality of life [33-34,37,44].
Further research into factors underlying this apparent disconnect between perceived and objective physical function in older Veterans with PTSD is warranted.

This study has several notable strengths, including the consideration of depression in our analyses. The clinical presentation of PTSD often includes comorbid depression [45], which is also associated with poor health and functioning [46-47]. Previous studies of PTSD have typically not assessed or controlled for depression. Recognizing that depression may play a unique role in health and functional status, we controlled for the effects of depression in our analyses. Interestingly, depression alone was not a significant predictor of self-reported health status or physical performance in this sample of Veterans (data not shown). Our results provide preliminary evidence for a higher relative contribution of PTSD to self-rated health status and physical performance after controlling for depression. Further consideration of how these two conditions influence and reinforce one another to negatively affect health is warranted.

Our results should be interpreted with consideration of several limitations. First, our diagnoses of PTSD and depression were based on retrospective reviews of the medical record, which limits our ability to determine the etiology of the diagnosis, the severity and chronicity of the symptoms, and whether a dose-response relationship exists. Furthermore, our EMR data extraction did not specify a time period for PTSD or depression diagnosis and it is possible that some of these cases were resolved but not updated in the medical record. More rigorous evaluations of PTSD symptoms including clinical assessments of PTSD diagnostic status and symptom severity are preferred, but were not available for this secondary analysis study. Second, the inclusion criteria of the parent study limit our ability to generalize these findings to individuals with PTSD who are not overweight or who are not at risk for diabetes. However, overweight/obesity and metabolic conditions are also pervasive in military Veterans with PTSD [5,9]. Individuals were required to be deconditioned to enter this study, which also limits the generalizability of our findings. Third, this retrospective study prevents us from examining a causal relationship between PTSD and functional limitations. Longitudinal research exploring the causal relationship between PTSD, health, and functional status are needed. Fourth, although the age range of our sample (60-89 yr) suggests that the majority of these Veterans served during the Vietnam era, we did not directly assess military service era. 
Finally, we did not assess other behavioral factors such as smoking, alcohol consumption, or sleep, which may affect functional status.

\section{CONCLUSIONS}

This study extends the current knowledge of PTSD and diminished health status by examining physical function and physical performance while controlling for relevant health and psychiatric variables. After controlling for depression, age, race, BMI, and comorbidities, we found a robust and significant association between PTSD and lower-limb function and self-reported health status. The results of this study emphasize the importance of routinely assessing physical function and related health behaviors in military Veterans and Veterans with PTSD over time. Prospective studies are needed to develop our understanding of how PTSD interplays with function and the aging process, identify the mechanisms underlying these functional trajectories over time, and develop tailored rehabilitation interventions as a secondary prevention strategy for the physical morbidity associated with PTSD.

\section{ACKNOWLEDGMENTS}

\section{Author Contributions:}

Study concept and design: K. S. Hall, M. C. Morey, J. C. Beckham, H. B. Bosworth.

Acquisition of data (generating and gathering): K. S. Hall, M. C. Morey, R. Sloane, C. F. Pieper.

Analysis and interpretation of data: K. S. Hall, M. C. Morey, J. C. Beckham, H. B. Bosworth, R. Sloane, C. F. Pieper.

Critical revision of manuscript for important intellectual content:

K. S. Hall, M. C. Morey, J. C. Beckham, H. B. Bosworth, R. Sloane, C. F. Pieper.

Statistical analysis: K. S. Hall, M. C. Morey, R. Sloane, C. F. Pieper. Obtained funding: M. C. Morey, K. S. Hall.

Administrative, technical, or material support: K. S. Hall,

M. C. Morey.

Study supervision: M. C. Morey, K. S. Hall.

Financial Disclosures: The authors have declared that no competing interests exist.

Funding/Support: This material was based on work supported by the VA (grants RRD-E782MM to Dr. Hall; IIR-06-252-3 to Dr. Morey and RCS 08-027 to Dr. Bosworth) and the National Institute on Aging at the National Institutes of Health (grant AG028716 to Dr. Morey). Additional Contributions: We wish to acknowledge and thank the investigative team associated with the Enhanced Fitness study: David Edelman, MD; William S. Yancy Jr, MD; Jennifer B. Green, MD;
Helen Lum, MD; Matthew J. Peterson, PhD; Patricia A. Cowper, PhD; Kim M. Huffman, MD; James T. Cavanaugh, PhD; Jennifer G. Chapman, BASW; Megan P. Pearson, MA; Teresa A. Howard, AA; Carola C. Ekelund, PT; Beverly L McCraw, MA; Joi B. Deberry, BS, RN, BSN; and Gregory A. Taylor, PhD. We also wish to thank Lawrence Landerman, $\mathrm{PhD}$, for his counsel and support during this study. And finally, we are grateful for the participating Veterans and their families for their gracious contribution to this research.

Institutional Review: The Durham VA institutional review board reviewed and approved the research protocol, and written consent was obtained from all participants.

Participant Follow-Up: The authors do not plan to inform participants of the publication of this study.

Disclaimer: The views expressed by the authors do not necessarily reflect the views of the VA.

\section{REFERENCES}

1. U.S. Census Bureau. American community survey public use microdata sample. Washington (DC): National Center for Veterans Analysis and Statistics; 2011.

2. Otter L, Currie J. A long time getting home: Vietnam Veterans' experiences in a community exercise rehabilitation programme. Disabil Rehabil. 2004;26(1):27-34.

[PMID:14660196] http://dx.doi.org/10.1080/09638280410001645067

3. Eisen SA, Griffith KH, Xian H, Scherrer JF, Fischer ID, Chantarujikapong S, Hunter J, True WR, Lyons MJ, Tsuang MT. Lifetime and 12-month prevalence of psychiatric disorders in 8,169 male Vietnam War era veterans. Mil Med. 2004;169(11):896-902. [PMID:15605939]

4. Thompson WW, Gottesman II, Zalewski C. Reconciling disparate prevalence rates of PTSD in large samples of US male Vietnam veterans and their controls. BMC Psychiatry. 2006;6:19. [PMID:16670009] http://dx.doi.org/10.1186/1471-244X-6-19

5. Vieweg WV, Julius DA, Bates J, Quinn JF 3rd, Fernandez A, Hasnain M, Pandurangi AK. Posttraumatic stress disorder as a risk factor for obesity among male military veterans. Acta Psychiatr Scand. 2007;116(6):483-87.

[PMID:17997727]

http://dx.doi.org/10.1111/j.1600-0447.2007.01071.x

6. Vieweg WV, Julius DA, Fernandez A, Tassone DM, Narla SN, Pandurangi AK. Posttraumatic stress disorder in male military veterans with comorbid overweight and obesity: psychotropic, antihypertensive, and metabolic medications. Prim Care Companion J Clin Psychiatry. 2006;8(1):25-31. [PMID:16862250] http://dx.doi.org/10.4088/PCC.v08n0104

7. Boscarino JA. Posttraumatic stress disorder and physical illness: Results from clinical and epidemiologic studies. 
Ann N Y Acad Sci. 2004;1032:141-53. [PMID:15677401] http://dx.doi.org/10.1196/annals.1314.011

8. Boscarino JA. A prospective study of PTSD and early-age heart disease mortality among Vietnam veterans: Implications for surveillance and prevention. Psychosom Med. 2008;70(6):668-76. [PMID:18596248] http://dx.doi.org/10.1097/PSY.0b013e31817bccaf

9. Heppner PS, Crawford EF, Haji UA, Afari N, Hauger RL, Dashevsky BA, Horn PS, Nunnink SE, Baker DG. The association of posttraumatic stress disorder and metabolic syndrome: A study of increased health risk in veterans. BMC Med. 2009;7:1. [PMID:19134183] http://dx.doi.org/10.1186/1741-7015-7-1

10. Dedert EA, Calhoun PS, Watkins LL, Sherwood A, Beckham JC. Posttraumatic stress disorder, cardiovascular, and metabolic disease: A review of the evidence. Ann Behav Med. 2010;39(1):61-78. [PMID:20174903] http://dx.doi.org/10.1007/s12160-010-9165-9

11. Schnurr PP, Spiro A 3rd, Paris AH. Physician-diagnosed medical disorders in relation to PTSD symptoms in older male military veterans. Health Psychol. 2000;19(1):91-97. [PMID:10711592] http://dx.doi.org/10.1037/0278-6133.19.1.91

12. Schnurr PP, Green BL. Understanding relationships among trauma, post-traumatic stress disorder, and health outcomes. Adv Mind Body Med. 2004;20(1):18-29. [PMID:15068106]

13. Friedman MJ, McEwen BS. Posttraumatic stress disorder, allostatic load, and medical illness. Trauma and health: Physical health consequences of exposure to extreme stress. Washington (DC): American Psychological Association; 2004.

14. Pietrzak RH, Goldstein RB, Southwick SM, Grant BF. Physical health conditions associated with posttraumatic stress disorder in U.S. older adults: Results from wave 2 of the National Epidemiologic Survey on Alcohol and Related Conditions. J Am Geriatr Soc. 2012;60(2):296-303. [PMID:22283516] http://dx.doi.org/10.1111/j.1532-5415.2011.03788.x

15. Jakupcak M, Luterek J, Hunt S, Conybeare D, McFall M. Posttraumatic stress and its relationship to physical health functioning in a sample of Iraq and Afghanistan War veterans seeking postdeployment VA health care. J Nerv Ment Dis. 2008;196(5):425-28. [PMID:18477887] http://dx.doi.org/10.1097/NMD.0b013e31817108ed

16. Buckley TC, Mozley SL, Bedard MA, Dewulf AC, Greif J. Preventive health behaviors, health-risk behaviors, physical morbidity, and health-related role functioning impairment in veterans with post-traumatic stress disorder. Mil Med. 2004;169(7):536-40. [PMID:15291186]

17. Magruder KM, Frueh BC, Knapp RG, Davis L, Hamner MB, Martin RH, Gold PB, Arana GW. Prevalence of post- traumatic stress disorder in Veterans Affairs primary care clinics. Gen Hosp Psychiatry. 2005;27(3):169-79.

[PMID:15882763]

http://dx.doi.org/10.1016/j.genhosppsych.2004.11.001

18. Barile JP, Thompson WW, Zack MM, Krahn GL, HornerJohnson W, Haffer SC. Activities of daily living, chronic medical conditions, and health-related quality of life in older adults. J Ambul Care Manage. 2012;35(4):292-303. [PMID:22955089]

http://dx.doi.org/10.1097/JAC.0b013e31826746f5

19. Thompson WW, Zack MM, Krahn GL, Andresen EM, Barile JP. Health-related quality of life among older adults with and without functional limitations. Am J Public Health. 2012;102(3):496-502. [PMID:22390514] http://dx.doi.org/10.2105/AJPH.2011.300500

20. Perera S, Mody SH, Woodman RC, Studenski SA. Meaningful change and responsiveness in common physical performance measures in older adults. J Am Geriatr Soc. 2006;54(5):743-49. [PMID:16696738]

http://dx.doi.org/10.1111/j.1532-5415.2006.00701.x

21. Gill TM, Allore H, Holford TR, Guo ZC. The development of insidious disability in activities of daily living among community-living older persons. Am J Med. 2004;117(7): 484-91. [PMID:15464705]

http://dx.doi.org/10.1016/j.amjmed.2004.05.018

22. Sarkisian CA, Liu HH, Gutierrez PR, Seeley DG, Cummings SR, Mangione CM; The Study of Osteoporotic Fractures Research Group. Modifiable risk factors predict functional decline among older women: A prospectively validated clinical prediction tool. J Am Geriatr Soc. 2000;48(2):170-78. [PMID:10682946]

23. Guralnik JM, Ferrucci L, Pieper CF, Leveille SG, Markides KS, Ostir GV, Studenski S, Berkman LF, Wallace RB. Lower extremity function and subsequent disability: Consistency across studies, predictive models, and value of gait speed alone compared with the short physical performance battery. J Gerontol A Biol Sci Med Sci. 2000;55(4):M221-31. [PMID:10811152] http://dx.doi.org/10.1093/gerona/55.4.M221

24. Rantanen T, Guralnik JM, Foley D, Masaki K, Leveille S, Curb JD, White L. Midlife hand grip strength as a predictor of old age disability. JAMA. 1999;281(6):558-60.

25. Wennie Huang WN, Perera S, VanSwearingen J, Studenski SA. Performance measures predict onset of activity of daily living difficulty in community-dwelling older adults. J Am Geriatr Soc. 2010;58(5):844-52. [PMID:20406319] http://dx.doi.org/10.1111/j.1532-5415.2010.02820.x

26. Hall KS, Pieper CF, Edelman DE, Yancy WS Jr, Green JB, Lum H, Peterson MJ, Sloane R, Cowper PA, Bosworth HB, Huffman KM, Cavanaugh JT, Chapman JG, Pearson MP, Howard TA, Ekelund CC, McCraw BL, Burrell JB, Taylor GA, Morey MC. Lessons learned when innovations go 
awry: A baseline description of a behavioral trial-the Enhancing Fitness in Older Overweight Veterans with Impaired Fasting Glucose study. Transl Behav Med. 2011; 1(4):573-87. [PMID:22866170] http://dx.doi.org/10.1007/s13142-011-0075-6

27. Morey MC, Pieper CF, Edelman DE, Yancy WS Jr, Green JB, Lum H, Peterson MJ, Sloane R, Cowper PA, Bosworth HB, Huffman KM, Cavanaugh JT, Hall KS, Pearson MP, Taylor GA. Enhanced fitness: A randomized controlled trial of the effects of home-based physical activity counseling on glycemic control in older adults with prediabetes mellitus. J Am Geriatr Soc. 2012;60(9):1655-62.

[PMID:22985140]

http://dx.doi.org/10.1111/j.1532-5415.2012.04119.x

28. Fillenbaum G. Multidimensional functional assessment of older adults: The Duke older Americans resources and services procedure. Hillsdale (NJ): Erlbaum; 1988.

29. Ware JE, Sherbourne CD. The MOS 36-item Short-Form Health Survey (SF-36): I. Conceptual framework and item selection. Med Care. 1992;30(6):473-83. [PMID:1593914] http://dx.doi.org/10.1097/00005650-199206000-00002

30. Guralnik JM, Simonsick EM, Ferrucci L, Glynn RJ, Berkman LF, Blazer DG, Scherr PA, Wallace RB. A short physical performance battery assessing lower extremity function: Association with self-reported disability and prediction of mortality and nursing home admission. J Gerontol. 1994;49(2):M85-94. [PMID:8126356]

http://dx.doi.org/10.1093/geronj/49.2.M85

31. Balke B. A simple field test for the assessment of physical fitness. Rep 63-6. Rep Civ Aeromed Res Inst US. 1963; 63:1-8. [PMID:14131272]

32. Tabachnick BG, Fidell LS. Using multivariate statistics. 4th ed. Boston (MA): Allyn \& Bacon; 2001.

33. Maciejewski ML, Liu CF, Fihn SD. Performance of comorbidity, risk adjustment, and functional status measures in expenditure prediction for patients with diabetes. Diabetes Care. 2009;32(1):75-80. [PMID:18945927]

http://dx.doi.org/10.2337/dc08-1099

34. Pietz K, Ashton CM, McDonell M, Wray NP. Predicting healthcare costs in a population of Veterans Affairs beneficiaries using diagnosis-based risk adjustment and selfreported health status. Med Care. 2004;42(10):1027-35. [PMID:15377936] http://dx.doi.org/10.1097/00005650-200410000-00012

35. Stam PJ, van Vliet RC, van de Ven WP. Diagnostic, pharmacy-based, and self-reported health measures in risk equalization models. Med Care. 2010;48(5):448-57. [PMID:20393368] http://dx.doi.org/10.1097/MLR.0b013e3181d559b4

36. Fleishman JA, Cohen JW, Manning WG, Kosinski M. Using the SF-12 health status measure to improve predic- tions of medical expenditures. Med Care. 2006;44(5, Suppl):I54-63. [PMID:16625065]

37. Rendas-Baum R, Miller K. Predicting a patient's future medical visits: A comparison of quality of life and clinical variables. New Orleans (LA): International Society for Pharmacoeconomics and Outcomes Research; 2013.

38. Otis JD, Gregor K, Hardway C, Morrison J, Scioli E, Sanderson K. An examination of the co-morbidity between chronic pain and posttraumatic stress disorder on US veterans. Psychol Serv. 2010;7(2):126-35.

http://dx.doi.org/10.1037/a0020512

39. Spiro A 3rd, Hankin CS, Mansell D, Kazis LE. Posttraumatic stress disorder and health status: The veterans health study. J Ambul Care Manage. 2006;29(1):71-86. [PMID:16340621] http://dx.doi.org/10.1097/00004479-200601000-00008

40. Pahor M, Blair SN, Espeland M, Fielding R, Gill TM, Guralnik JM, Hadley EC, King AC, Kritchevsky SB, Maraldi C, Miller ME, Newman AB, Rejeski WJ, Romashkan S, Studenski S; LIFE Study Investigators. Effects of a physical activity intervention on measures of physical performance: Results of the lifestyle interventions and independence for Elders Pilot (LIFE-P) study. J Gerontol A Biol Sci Med Sci. 2006;61(11):1157-65.

[PMID:17167156] http://dx.doi.org/10.1093/gerona/61.11.1157

41. Rikli RE, Jones CJ. Functional fitness normative scores for community-residing older adults, ages 60-94. J Aging Phys Act. 1999;7(2):162-81.

42. Mathiowetz V, Kashman N, Volland G, Weber K, Dowe M, Rogers S. Grip and pinch strength: Normative data for adults. Arch Phys Med Rehabil. 1985;66(2):69-74. [PMID:3970660]

43. Bohannon RW. Hand-grip dynamometry predicts future outcomes in aging adults. J Geriatr Phys Ther. 2008;31(1): 3-10. [PMID:18489802] http://dx.doi.org/10.1519/00139143-200831010-00002

44. Patrick DL, Kinne S, Engelberg RA, Pearlman RA. Functional status and perceived quality of life in adults with and without chronic conditions. J Clin Epidemiol. 2000;53(8): 779-85. [PMID:10942859] http://dx.doi.org/10.1016/S0895-4356(00)00205-5

45. Ginzburg K, Ein-Dor T, Solomon Z. Comorbidity of posttraumatic stress disorder, anxiety and depression: a 20-year longitudinal study of war veterans. J Affect Disord. 2010;123(1-3):249-57. [PMID:19765828]

http://dx.doi.org/10.1016/j.jad.2009.08.006

46. Chwastiak LA, Rosenheck RA, Kazis LE. Association of psychiatric illness and obesity, physical inactivity, and smoking among a national sample of veterans. Psychosomatics. 2011;52(3):230-36. [PMID:21565594]

http://dx.doi.org/10.1016/j.psym.2010.12.009 
47. Dalle Carbonare L, Maggi S, Noale M, Giannini S, Rozzini R, Lo Cascio V, Crepaldi G; ILSA Working Group; The Italian Longitudinal Study on Aging (ILSA). Physical disability and depressive symptomatology in an elderly population: A complex relationship. Amer J Geriatr Psychiatry. 2009;17(2):144-54. [PMID:19172682]

http://dx.doi.org/10.1097/JGP.0b013e31818af817

Submitted for publication April 11, 2013. Accepted in revised form September 11, 2013.
This article and any supplementary material should be cited as follows:

Hall KS, Beckham JC, Bosworth HB, Sloane R, Pieper CF, Morey MC. PTSD is negatively associated with physical performance and physical function in older overweight military Veterans. J Rehabil Res Dev. 2014; 51(2):285-96.

http://dx.doi.org/10.1682/JRRD.2013.04.0091

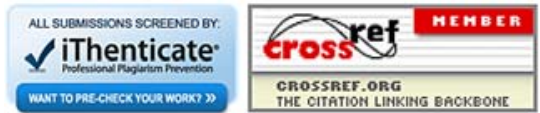


